\title{
Correction to: Vertical Redistribution of Soil Organic Carbon Pools After Twenty Years of Nitrogen Addition in Two Temperate Coniferous Forests
}

Stefan J. Forstner, ${ }^{1 *} \odot$ Viktoria Wechselberger, ${ }^{1}$ Stefanie Müller, ${ }^{1}$ Katharina M. Keiblinger, ${ }^{1}$ Eugenio Díaz-Pinés, ${ }^{1}$ Wolfgang Wanek, ${ }^{2}$ Patrick Schleppi, ${ }^{3}$ Frank Hagedorn, ${ }^{3}$ Per Gundersen ${ }^{4}$ Michael Tatzber, ${ }^{1,5}$ Martin H. Gerzabek, ${ }^{1}$ and Sophie Zechmeister-Boltenstern ${ }^{1}$

\footnotetext{
${ }^{1}$ Institute of Soil Research, Department of Forest and Soil Sciences, University of Natural Resources and Life Sciences (BOKU), 1190 Vienna, Austria; ${ }^{2}$ Department of Microbiology and Ecosystem Science, University of Vienna, 1090 Vienna, Austria; ${ }^{3}$ Swiss Federal Institute for Forest, Snow and Landscape Research (WSL), 8903 Birmensdorf, Switzerland; ${ }^{4}$ Department of Geosciences and Natural Resource Management, University of Copenhagen, 1958 Frederiksberg C, Denmark; ${ }^{5}$ Division of Radiation Protection, Department of Radiation Protection and Radiochemistry, Austrian Agency for Health and Food Safety (AGES), 1220 Vienna, Austria
}

\section{Correction to: ECOSYSTEMS HTTPS:/DOI.ORG/10.1007/s10021-018-0275-8}

In the article by Forstner et al. (2018), the surnames of co-authors Katharina M. Keiblinger and Patrick Schleppi were misspelled. We apologize and ask readers to cite the corrected version of the article as presented here.

Further, equation (1) was incorrectly formulated in the original article. The original equation shown is only correct if $\theta_{i}$ is the volume percentage of roots and stones. If $\theta_{i}$ represents the volume fraction of

published online 22 January 2019

The original article can be found online at https://doi.org/10.1007/s100 21-018-0275-8.

*Corresponding author; e-mail: stefan.forstner@boku.ac.at roots and stones as stated in the original article, equation (1) has to be reformulated as follows:

$$
\operatorname{SOCP}_{i}=\rho_{\mathrm{B}, i} \times d_{i} \times \operatorname{SOC}_{i} \times\left(1-\theta_{i}\right)
$$

Results and conclusion presented in the original article are not affected by this correction as soil organic $\mathrm{C}$ pools have been calculated using the volume fraction and equation (1) in the corrected form. published online 22 January 2019

The original article can be found online at https://doi.org/10.1007/s100 21-018-0275-8

*Corresponding author; e-mail: stefan.forstner@boku.ac.at 